\title{
BMJ Open Use of symptom-relieving drugs before and after surgery for urinary incontinence in women: a cohort study
}

\author{
Rikke Guldberg, ${ }^{1,2}$ Søren Brostrøm, ${ }^{3}$ Ulrik Schiøler Kesmodel, ${ }^{4}$ Linda Kærlev, ${ }^{1,2}$ \\ Jesper Kjær Hansen, ${ }^{1,2}$ Jesper Hallas, ${ }^{5}$ Bente Mertz Nørgård ${ }^{1,2}$
}

To cite: Guldberg R, Brostrøm S, Kesmodel US, et al. Use of symptomrelieving drugs before and after surgery for urinary incontinence in women: a cohort study. BMJ Open 2013;3:e003297.

doi:10.1136/bmjopen-2013003297

- Prepublication history and additional material for this paper is available online. To view these files please visit the journal online (http://dx.doi.org/10.1136/ bmjopen-2013-003297).

Received 24 May 2013 Revised 16 October 2013 Accepted 17 October 2013

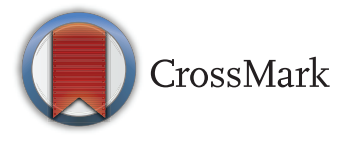

For numbered affiliations see end of article.

\section{Correspondence to} Dr Rikke Guldberg; Rikke.Guldberg.Soerensen@ rsyd.dk

\begin{abstract}
Objective: To describe the use of symptom-relieving drugs (antimuscarinic drugs or duloxetine) before and after surgery for urinary incontinence (UI); and for those with use of antimuscarinic drugs or duloxetine before surgery, to estimate the risk of being a postoperative user, relative to those without use before surgery.

Design: A historical population-based cohort study. Setting: Denmark.

Participants: Women $\geq 18$ years with a first-time surgical procedure for $\mathrm{UI}$ from the county of Funen, Denmark between 1 January 1996 and 31 December 2006, extended to the Region of Southern Denmark from 1 January 2007 to the end of 2010. For these women, data on redeemed prescriptions \pm 365 days of date of surgery were extracted.
\end{abstract}

Main outcome measures: Effect of preoperative use of antimuscarinic drugs or duloxetine on the risk of being a postoperative user of these drugs.

Results: Of 2151 women with a first-time surgical procedure for $\mathrm{UI}, 358(16.6 \%)$ were preoperative users of antimuscarinic drugs or duloxetine and 1793 were not $(83.4 \%)$. A total of $110(30.7 \%)$ of the preoperative users also redeemed prescriptions for these drugs within 0-60 days after surgery, and $152(42.5 \%)$ of the preoperative users redeemed prescriptions for these drugs within 61-365 days after surgery. Among preoperative non-users, $25(1.4 \%)$ and $145(8.1 \%)$ redeemed prescriptions within 0-60 and 61-365 days after surgery, respectively. Presurgery exposure to antimuscarinic drugs or duloxetine was a strong risk factor of postoperative drug use, both within 0-60 days (adjusted OR=33.0, 95\% $\mathrm{Cl} 20.0$ to 54.7) and 61-365 days ( $\mathrm{OR}=7.2,95 \% \mathrm{Cl} 5.4$ to 9.6 ).

Conclusions: A substantial number of women will continue to be prescribed symptom-relieving drugs after surgery for $\mathrm{UI}$ within a year of follow-up. Only a minority of preoperative non-users initiated usage of symptomrelieving drugs after surgery. Compared with other factors included in the regression model, preoperative use of antimuscarinic drugs or duloxetine was the strongest risk factor for postoperative use.

\section{INTRODUCTION}

Urinary incontinence (UI) is a very prevalent disorder among women, ${ }^{1}$ and a wide array of

\section{Strengths and limitations of this study}

- A population-based study.

- In total 2151 women included.

- High quality of data sources and complete information in the follow-up period for all included women.

- Adjustment for several factors: age, procedure type, preoperative oestrogen use, comorbidity, educational level and personal annual income.

- Redeemed prescriptions were used as a proxy for drug use.

- No data on type of urinary incontinence or urodynamic studies.

options for clinical managements exists. Current best practice is a stepwise strategy moving from conservative treatments such as behavioural alteration, pelvic floor muscle training and weight loss to pharmacological treatment and, in selected cases, surgery. ${ }^{2}$

There are different pharmacological options to relieve the symptoms of UI, including antimuscarinic drugs and duloxetine. Antimuscarinic drugs remain the mainstay in the treatment of urgency UI, mixed UI as well as the overactive bladder syndrome. ${ }^{3}$ Antimuscarinics reversibly block muscarinic receptors in the bladder wall, acting primarily by increasing bladder capacity rather than by ablating detrusor overactivity. Although the site of action has been thought to be M2 and M3 receptors in detrusor smooth muscle during contraction, there is growing evidence that the therapeutic response might also be the result of antagonist effects on muscarinic receptors on afferent neurons ${ }^{4}$ as well as central modulation. Duloxetine, a selective serotonin-reuptake and norepinephrinereuptake inhibitor, is predominantly used as an antidepressant, but has also been licensed in some European countries for stress UI. Presumably duloxetine acts by central modulations, causing an increase in the urethral sphincter tone. ${ }^{5}$ 
During the last decades, the surgical treatments of UI in women have improved with the introduction of minimally invasive suburethral sling procedures for UI, ${ }^{6-8}$ submucosal intraurethal injections of bulking agents ${ }^{9}$ and intravesical injections of botulinum toxin ${ }^{10}$; and the number of surgeries for UI has been increasing as well. ${ }^{11} 12$

Three small studies by Segal et al ${ }^{13}(\mathrm{n}=98)$, Yoo and $\operatorname{Kim}^{14}(\mathrm{n}=84)$ and Barber et al ${ }^{15}(\mathrm{n}=162)$ have shown that nearly $40 \%$ of preoperative antimuscarinic drug users continued the use after surgery for UI.

This topic is highly relevant in advising women who are candidates for surgical treatment for UI, if the results could be confirmed in larger studies. Women being counselled for incontinence surgery would be better served with information on the likelihood of both having to remain on drug use or having to start the use for other lower urinary tract symptoms following their procedure; therefore, the purpose of this study was to assess the use of symptom-relieving drugs before and after surgery for UI in a larger population and to examine the possible risk factors of postoperative drug use.

\section{MATERIALS AND METHODS}

\section{Study population and settings}

Data on all first-time surgical procedures for UI in women during the study period from 1 January 1996 to 31 December 2010 were retrieved from the Danish National Patient Registry (NPR). ${ }^{16}$ The International Classification of Diseases (ICD) procedure codes for data extraction are listed in online supplementary appendix 1 . The study population included women $\geq 18$ years undergoing a first-time surgical procedure for UI in a hospital in the county of Funen (four hospitals), Denmark between 1 January 1996 and 31 December 2006. For the period 2007 through 2010, the geographical area was extended to include all hospitals from the Region of Southern Denmark (including Funen, a total of 13 hospitals). The latter was due to a change in the structure of healthcare in Denmark from counties to regions in 2007. Women with concomitant or prior surgery for pelvic organ prolapse were not excluded. In women with more than one procedure code for UI in the study period, the first code was chosen as the included procedure.

\section{Data sources}

Data for this study were retrieved from three Danish registers: the NPR, the Odense University Pharmacoepidemiologic Database (OPED) and the Statistics Denmark.

The NPR was established in 1977; it contains data on discharges from public hospitals in Denmark. The completeness of recordings has been estimated to be $99.4 \%{ }^{17}$ The registry contains information about the unique personal identification number (CPN) assigned to all Danish citizens, the dates of admission and discharge, the surgical procedures performed, and up to 20 diagnoses for every discharge, classified according to the ICD-8 (1977-1993) and ICD-10 (1994 and onwards) ${ }^{18} 19$ as well as codes from the Danish classification system of surgical procedures. ${ }^{20}$

Information on relevant drugs (antimuscarinic drugs, duloxetine and oestrogens) was retrieved within 19952011 for the entire study population from OPED by using CPN.

OPED contains person-identifiable data with complete coverage on all computerised prescription reimbursements from the County of Funen (population 2006: $479000)$ from 1990 and from January 2007 onwards extended to the whole Region of Southern Denmark (population 1.2 million). The age and gender distribution of this population is very similar to that of the Danish population as a whole (2006: 5.4 mio.), and the prescription of drugs is very similar to the national average. $^{21}$ OPED is pharmacy based and captures all reimbursed prescriptions.

Prescription reimbursements are offered as a part of the National Health Service to all legal inhabitants of Denmark and given independently of patient income. Each record includes the CPN, the date of purchase, the pharmacy, a full account of what has been purchased, including brand name, Anatomical Therapeutic Chemical (ATC) classification code, total defined daily dose (DDD), dose unit and quantity. The database does not contain information on indicative diagnoses, drugs sold over the counter or drugs not reimbursed by the county authority (mainly oral contraceptives, sedatives and hypnotics). Data on the highest attained educational level and annual income were retrieved from the Danish Integrated Database for Labor Market Research at the Statistics of Denmark. This database contains annually updated socioeconomic data for each Danish citizen, mainly supplied by tax authorities, educational institutions and employment services. ${ }^{22}$

\section{Study drugs}

Included drugs were antimuscarinic drugs (tolterodine (ATC G04BD07), solifenacin (ATC G04BD08), trospium chloride (ATC G04BD09), darifenacin (ATC G04BD10), fesoterodine (ATC G04BD11), oxybutynin (ATC G04BD04), flavoxate (ATC G04BD02)), duloxetine (ATC N06AX21) (only brand name Yentreve) and oestrogens (ATC G03C). Propiverine (ATC G04BD6) has not been licensed in Denmark.

\section{Exposed and unexposed cohorts}

Exposed cohort: All women $\geq 18$ years undergoing a firsttime surgical procedure for UI between 1 January 1996 and 31 December 2010 in the county of Funen/Region of Southern Denmark and having redeemed one or more prescriptions for antimuscarinic drugs or duloxetine for UI within 365 days preceding the date of surgery (index date). 
Unexposed cohort: All women $\geq 18$ years undergoing a first-time surgical procedure for UI between 1 January 1996 and 31 December 2010 in the county of Funen/ Region of Southern Denmark without having redeemed similar prescriptions within the same time frame.

\section{Outcome data}

For exposed and unexposed women, the first-time outcome was the use of symptom-relieving drugs, defined as having redeemed at least one prescription for antimuscarinic drugs or duloxetine within (1) 60 days after the index date (short term postoperatively) and (2) 61-365 days after the index date (long term postoperatively). These outcomes were not mutually exclusive, that is, a woman might be classified both as a short-term and long-term user postoperatively.

\section{Covariates}

The use of symptom-relieving drugs might be affected by age, type of procedure, use of oestrogen, comorbidity, educational level, annual income and calendar time; therefore, these variables were included in the analysis as potential confounders.

Type of procedures: The types of UI surgery were divided into four groups according to the surgical procedure code: (1) mid-urethral sling procedures with transobturator route (toMUS), (2) mid-urethral sling procedures with retropubic route (rpMUS), (3) bulking procedures and (4) other types of UI surgeries.

Oestrogen: To adjust for preoperative oestrogen use, women were divided into those who had redeemed at least one prescription for oestrogens within 365 days prior to surgery, and those who had no preoperative oestrogen use. Both systemic and local oestrogens were included.

Comorbidity: Comorbidity was classified according to the Charlson comorbidity index (CCI),${ }^{23}$ a well-known, validated and widely used quantitative measure of comorbid illness. ${ }^{24}{ }^{25}$ It assigns different weights (1, 2, 3 and 6) to 19 different disease categories specified by medical condition and severity (eg, diabetes, cardiovascular diseases, chronic pulmonary, renal, liver and connective tissue diseases). For each woman, the CCI was computed based on her complete hospital discharge history from the NPR since 1977. A categorised version of the CCI with score values grouped were used: 0 (low), 1-2 (medium) and 3+ (high). ${ }^{26}$

Socioeconomic status: To measure socioeconomic status, information on education and annual income for each woman was retrieved. Education was categorised according to the highest attained educational level as 'Basic' (basic school/high school education: 7-12 years of firsttime, secondary and grammar-school education), 'Secondary' (vocational education, 10-12 years of education) and 'Higher' (a university degree or an examination in another higher institution requiring on average a total of 13 years or more) ${ }^{27}$
On the basis of quartiles of annual income for each women at the year of her surgery, we categorised women in low (1st quartile), medium (2nd and 3rd quartile) and high income (4th quartile) recipients.

\section{Statistical analysis}

We describe in a flow chart the use of symptom-relieving drugs within the first 365 days after surgery for the two groups of users and non-users of drugs prior to surgery.

We also constructed contingency tables for the main study variables, and computed the OR, with $95 \%$ CI.

To analyse the significance of preoperative symptomrelieving drug use as a risk factor of postoperative use (short and long term), adjusted ORs were estimated by means of multivariate logistic regression models. Adjustment was made for age (18-39, 40-59, $\geq 60$ years (reference)), type of procedures (toMUS (reference), rpMUS, Bulking, others), education (basic (reference), secondary, higher), annual income (low (reference), middle, high), comorbidity (CCI 0 (reference), CCI 1-2, CCI 3 + ), calendar-year (1996-2006, 2007-2008 (reference), 2009-2010) and use of oestrogen within 365 days preceding surgery (No (reference), Yes).

All analyses were performed using Stata Release V.12.0.

\section{RESULTS}

A total of 2151 women had a first-time surgical procedure for UI between 1 January 1996 and 31 December 2010 (2073 had solitary UI surgery, and 78 had concomitant surgery for pelvic organ prolapse).

Of the 2151 women, $358(16.6 \%)$ were exposed to symptom-relieving drugs within 365 days before surgery, and $1793(83.4 \%)$ were not. The use of symptomrelieving drugs within 365 days after surgery is detailed in both these cohorts (figure 1).

\section{Women having redeemed prescriptions for} symptom-relieving drugs before surgery (exposed)

Of the 358 women with prior drug use of antimuscarinic drugs or duloxetine, $110(30.7 \%)$ women redeemed prescriptions for these drugs within 0-60 days after surgery, and 98 of the 358 women (26.8\%) did so within 61365 days after surgery (figure 1 ). On the other hand, 248 (69.3\%) women did not redeem a prescription for symptom-relieving drugs within 0-60 days after surgery, and the majority of these women $(192 / 358=53.6 \%)$ also abstained from symptom-relieving drugs during the time frame 61-365 days after surgery (figure 1). For the exposed women, the number of redeemed prescriptions was 1360 preoperatively (DDD $174.6(\mathrm{SD} \pm 202)$ ), postoperatively 126 (DDD $32.3(\mathrm{SD} \pm 63.5))$ within $0-60$ days and 984 (DDD $140.4(\mathrm{SD} \pm 234.3)$ ) within 61-365 days.

Women with no usage of symptom-relieving drugs before surgery (unexposed)

Only 25 of the 1793 (1.4\%) women redeemed a first-time prescription for symptom-relieving drugs within 0-60 days 
Figure 1 Women $(\mathrm{N}=2151)$ with first-time surgery for urinary incontinence (UI) and their use of symptom-relieving drugs for UI (antimuscarinic drugs and duloxetine) before and after surgery for UI. Exposed women had redeemed one or more prescriptions of antimuscarinic drugs or duloxetine within 365 days preceding the date of surgery, and unexposed women had not redeemed prescriptions of antimuscarinic drugs or duloxetine within 365 days preceding the date of surgery.

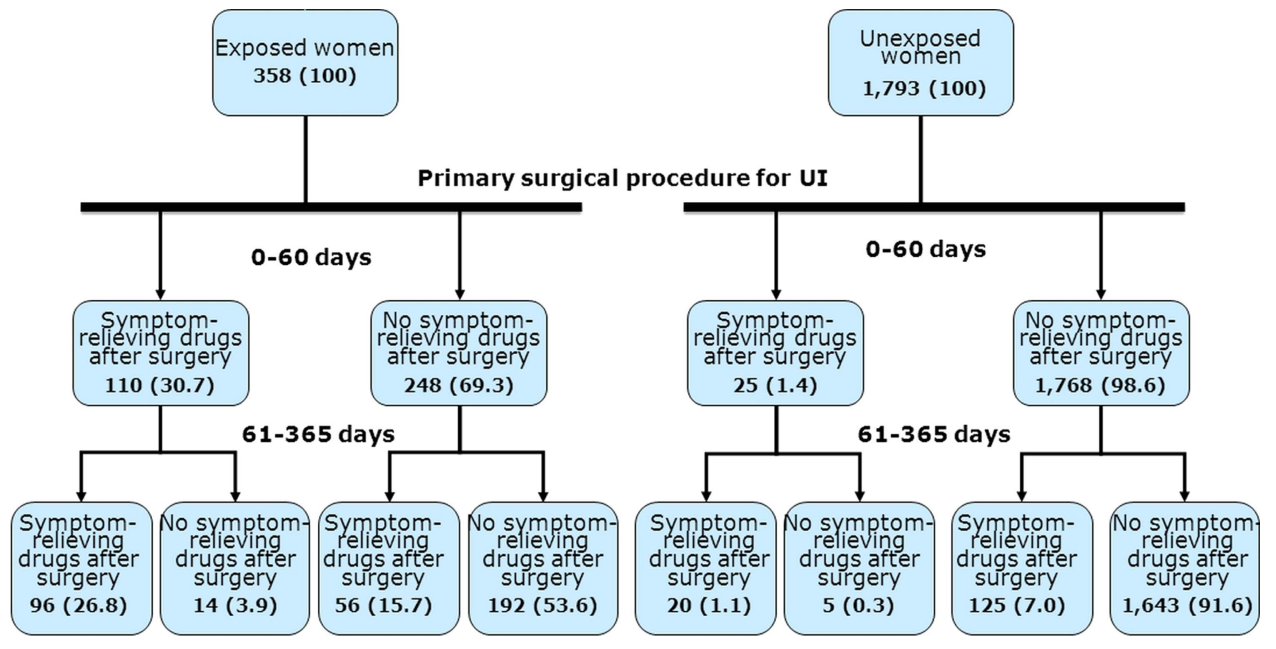

after surgery, and these women typically continued their use within 61-365 days after surgery (20 women; figure 1). Of the 1793 women who did not redeem prescription before surgery, $1768(98.6 \%)$ women remained non-users within 0-60 days after surgery, and the vast majority of these women $(1643 / 1793=91.6 \%)$ continued as non-users also within 61-365 days after surgery (figure 1). For the unexposed women, the number of redeemed prescriptions postoperatively was 129 (DDD $0.8(\mathrm{SD} \pm 8.8))$ within 0-60 days, and 403 (DDD 11.9 $(\mathrm{SD} \pm 54.8))$ within $61-365$ days.

The baseline characteristics of exposed and unexposed women are presented in table 1. The most commonly used procedures were rpMUS or toMUS. The exposed women were more likely to have had a transobturator mid-urethral sling or a bulking agent injection compared with unexposed women, where retropubic mid-urethral sling was the preferred procedure. The most commonly prescribed drugs prior to surgery were solifenacin and tolterodine. Compared with unexposed women, the exposed women tended to be older, to be more frequent oestrogen-users, to have higher comorbidity, a lower educational level and a lower annual income.

Among women with prior drug use, the unadjusted OR of being a short-term or long-term user of symptomrelieving drugs after surgery was 31.1 (95\% CI 19.9 to 49.4 ) and 8.4 (95\% CI 6.4 to 11.0$)$, respectively. The adjusted OR of being a short-term or long-term user of symptom-relieving drugs after surgery was 33.0 (95\% CI 20.0 to 54.7$)$ and 7.2 (95\% CI 5.4 to 9.6$)$, respectively. The details from logistic regression models presented in table 2 show the impact of each risk factor included. The preoperative use of antimuscarinic drugs or duloxetine was the absolutely strongest risk factor of postoperative use (both short and long term); that is, compared with preoperative drug use, no other factors contributed considerably to the OR of being a shortterm or long-term postoperative user.

\section{DISCUSSION}

Among 2151 women undergoing first-time surgery for UI, less than $20 \%$ had redeemed prescriptions for antimuscarinic drugs or duloxetine prior to surgery, and nearly $30 \%$ of these continued using the drugs within 2 months after surgery and typically stayed long-term users. Among the women without drug use before surgery, the vast majority continued to be non-users after surgery, with fewer than $9 \%$ redeeming a first-time prescription of the drugs.

Our study has several strengths: (1) it is a populationbased study in the sense that it covers all the relevant surgeries in a well-defined geographic area in Denmark, (2) The source of procedure has high coverage and validity. The NPR records $99.4 \%$ of all discharges from hospitals in Denmark, and the procedures in the NRP have been validated showing a moderate-to-high quality of the data with positive predictive values of $94-100 \%,{ }^{28-30}$ (3) the access to high quality data on prescriptions from the OPED that are representative for the Danish population, ${ }^{21}$ (4) information on several confounders such as comorbidity and socioeconomic status, (5) complete information in the follow-up period for all included women, (6) outcome data on postoperative drug prescriptions were obtained independently of exposure assessment preventing differential misclassification of the outcome, and finally (7) the drugs and the surgical procedures included in our study do not have other indications than UI, which strongly limits the number of alternative interpretations of our findings.

Our study also has limitations. Data on redeemed prescription are only a surrogate for drug intake. However, antimuscarinic drugs and especially duloxetine are expensive drugs with significant patient copayment, and we find it unlikely that these drugs to any major extent would be bought and not consumed. We had no data on patient symptomatology, that is, whether stress UI, urgency UI, mixed UI or overactive bladder syndrome was predominant, just as there were no available data on 
Table 1 Baseline characteristics of all included women $(\mathrm{N}=2151)$ having first-time surgery for urinary incontinence in Denmark, 1996-2010

\begin{tabular}{|c|c|c|}
\hline & $\begin{array}{l}\text { Exposed } \\
n=358 \\
(16.6 \%)\end{array}$ & $\begin{array}{l}\text { Unexposed } \\
n=1793 \\
(83.4 \%)\end{array}$ \\
\hline \multicolumn{3}{|l|}{ Mean age $( \pm S D)$, years } \\
\hline $\begin{array}{l}\text { (At time of first UI } \\
\text { surgery) }\end{array}$ & $60.9( \pm 12.7)$ & $54.5( \pm 12.6)$ \\
\hline \multicolumn{3}{|l|}{ Age groups $n(\%)$} \\
\hline $18-39$ & $13(3.6)$ & $199(11.1)$ \\
\hline $40-59$ & $151(42.2)$ & 956 (53.3) \\
\hline $60-$ & $194(54.2)$ & $638(35.6)$ \\
\hline \multicolumn{3}{|l|}{ Procedures n (\%) } \\
\hline rpMUS & $73(20.4)$ & $602(33.6)$ \\
\hline toMUS & $172(48.0)$ & $800(44.6)$ \\
\hline Bulking & $101(28.2)$ & $259(14.4)$ \\
\hline Others & $12(3.4)$ & $132(7.4)$ \\
\hline $\begin{array}{l}\text { Concomitant prolapse } \\
\text { surgery } n(\%)\end{array}$ & $11(3.1)$ & $67(3.7)$ \\
\hline \multicolumn{3}{|c|}{ Symptom-relieving medications $\mathrm{n}(\%)^{*}$} \\
\hline Solifenacin & $176(49.2)$ & - \\
\hline Tolterodine & $84(23.5)$ & - \\
\hline Fesoterodine & $63(17.6)$ & - \\
\hline Trospium chloride & $32(8.9)$ & - \\
\hline Oxybutynin & $29(8.1)$ & - \\
\hline Darifenacin & $14(3.9)$ & - \\
\hline Emepronium & $6(1.7)$ & - \\
\hline Duloxetine & $6(1.7)$ & - \\
\hline \multicolumn{3}{|l|}{ Oestrogen users n (\%)† } \\
\hline No & $135(37.7)$ & 1073 (59.8) \\
\hline Yes & 223 (62.3) & $720(40.2)$ \\
\hline \multicolumn{3}{|l|}{ Comorbidity (CCI) n (\%) } \\
\hline 0 & $214(59.8)$ & 1298 (72.3) \\
\hline $1-2$ & 107 (29.9) & $413(23.0)$ \\
\hline $3+$ & 37 (10.3) & $82(4.6)$ \\
\hline \multicolumn{3}{|l|}{ Educational level n (\%)‡ } \\
\hline Basic & $178(51.7)$ & 739 (41.8) \\
\hline Secondary & $125(36.3)$ & $645(36.5)$ \\
\hline Higher & 41 (11.9) & $383(21.7)$ \\
\hline \multicolumn{3}{|l|}{ Annual income $n(\%)$} \\
\hline Low (1st quartile) & $100(27.9)$ & $437(24.4)$ \\
\hline Middle (2nd-3rd quartile) & $206(57.6)$ & $871(48.6)$ \\
\hline High (4th quartile) & $52(14.5)$ & $485(27.0)$ \\
\hline \multicolumn{3}{|l|}{ Year of surgery $n(\%)$} \\
\hline 1996-2006 & $50(14.0)$ & 409 (22.8) \\
\hline 2007-2008 & $118(33.0)$ & $673(37.5)$ \\
\hline 2009-2010 & $190(53.0)$ & $711(39.7)$ \\
\hline \multicolumn{3}{|c|}{$\begin{array}{l}\text { *Does not sum up to } 100 \% \text {. Some women redeemed more than } \\
\text { one type of the drugs during the time period. } \\
\text { tWomen with at least one redeemed prescription of oestrogen } \\
\text { within } 365 \text { preceding surgery. } \\
\text { fUnknown highest attained educational level: } 40 \text { women. } \\
\text { CCI, Charlson comorbidity index; rpMUS, retropubic mid-urethral } \\
\text { sling; toMUS, transobturator mid-urethral sling; UI, urinary } \\
\text { incontinence. }\end{array}$} \\
\hline
\end{tabular}

findings in urodynamic studies. The exposed cohort was receiving symptom-relieving drugs, and thus these women most likely had predominantly mixed UI, whereas the unexposed women most likely had predominantly stress UI. We were not able to control for potential confounders such as body mass index, parity, grade of concomitant cystocele, severity of UI symptoms, intrinsic sphincter deficiency or menopausal status, which are well-known risk factors for persistent UI after surgery for UI. ${ }^{31-35}$ One might speculate whether duration of time with UI symptoms and preoperative conservative treatment could impact our estimates of postoperative drug use, as women in the exposed cohort could have longer disease duration before surgery than women in the unexposed cohort. This could be due to more extensive preoperative evaluations including urodynamic studies, as well as waiting time to evaluate the effect of drug treatment in the exposed cohort. However, to our knowledge, no studies have indicated that disease duration or conservative treatment of UI is a risk factor for postoperative drug use, and therefore we do not believe our estimates of postoperative drug use are influenced by duration of time with UI symptoms.

The currently available drugs for UI are expensive and have many side effects, ${ }^{36}$ and the long-term persistence of the use of antimuscarinic drugs as well as duloxetine is low (without regarding surgery). ${ }^{37-39}$ All the latter may contribute to the cessation of the drugs, and thus a reduction in the drug usage may not be explained entirely by the surgery. The reasons for cessation of drug use after surgery can be influenced by other factors as well. For example, misinterpretation of symptoms/investigations may lead to treatment of stress UI with symptom-relieving drugs.

The risk of initiating medical treatment after surgery for UI (based on de novo surgery) is small but well known. ${ }^{40}$

There was a low rate of concomitant pelvic reconstructive surgery, as was expected given the current practice in Scandinavia with a conservative approach of addressing the predominant problem of either pelvic organ prolapse or UI in sequential surgery. ${ }^{41}$ Age was higher among the exposed than among the unexposed women, and therefore, expectedly, we found a higher proportion of women with high comorbidity in the exposed group-and furthermore, not surprisingly, a higher proportion of Bulking procedures among exposed women as this procedure is often preferred in women with high comorbidity.

To our knowledge, this is the largest study to address changes in the use of symptom-relieving drugs in relation to surgery for UI, and having a large number of possible risk factors of postoperative use. Our results in this larger population are consistent with the previous smaller studies. ${ }^{13-15}$

Compared with the previous studies, our study included a larger number of women with UI surgery, estimated the risk of postoperatively symptom-relieving drug use with adjustment for a number of relevant covariates, and assessed the risk of both short-term and long-term use. Our study also showed that educational level, personal income and type of procedure did not seem to influence the risk of postoperative drug use. High comorbidity was found to significantly increase the 
Table 2 Risk factors of postoperative use of antimuscarinic drugs/duloxetine

\begin{tabular}{|c|c|c|c|c|c|c|}
\hline & \multirow{2}{*}{$\begin{array}{l}\text { Postoperative } \\
\text { non-use } \\
\text { Number }\end{array}$} & \multicolumn{2}{|c|}{ Postopetative short-term use } & \multirow{2}{*}{$\begin{array}{l}\text { Postoperative } \\
\text { non-use } \\
\text { Number }\end{array}$} & \multicolumn{2}{|c|}{$\begin{array}{l}\text { Postoperative long-term } \\
\text { use }\end{array}$} \\
\hline & & Number & OR $(95 \% \mathrm{Cl})$ & & Number & OR $(95 \% \mathrm{Cl})$ \\
\hline \multicolumn{7}{|c|}{ Preoperative use } \\
\hline No & 1768 & 25 & reference & 1648 & 145 & reference \\
\hline Yes & 248 & 110 & $33.0(20.0$ to 54.7$)$ & 145 & 152 & $7.2(5.4$ to 9.6$)$ \\
\hline \multicolumn{7}{|l|}{ Age group } \\
\hline $18-39$ & 209 & 3 & $0.3(0.1$ to 1.4$)$ & 204 & 8 & $0.3(0.1$ to 0.7$)$ \\
\hline $40-59$ & 1063 & 44 & 0.6 (0.3 to 0.9$)$ & 999 & 108 & $0.6(0.4$ to 0.8$)$ \\
\hline $60-$ & 744 & 88 & reference & 651 & 181 & reference \\
\hline \multicolumn{7}{|l|}{ Procedure } \\
\hline rpMUS & 659 & 16 & 0.6 (0.3 to 1.2$)$ & 612 & 63 & $0.6(0.4$ to 0.9$)$ \\
\hline toMUS & 894 & 78 & reference & 842 & 130 & reference \\
\hline Bulking & 322 & 38 & $1.2(0.7$ to 2.0$)$ & 262 & 98 & 0.5 (0.3 to 0.7$)$ \\
\hline Others & 141 & 3 & 0.5 (0.1 to 2.6$)$ & 138 & 6 & $0.3(0.1$ to 1.0$)$ \\
\hline \multicolumn{7}{|c|}{ Preoperative use of oestrogen* } \\
\hline No & 1159 & 49 & reference & 1090 & 118 & reference \\
\hline Yes & 857 & 86 & 0.8 (0.5 to 1.4$)$ & 764 & 179 & $1.0(0.7$ to 1.4$)$ \\
\hline \multicolumn{7}{|c|}{ Comorbidity $(\mathrm{CCl})$} \\
\hline 0 & 1442 & 70 & reference & 1352 & 160 & reference \\
\hline $1-2$ & 467 & 53 & 1.5 (0.9 to 2.4$)$ & 419 & 101 & 1.5 (1.1 to 2.0$)$ \\
\hline $3+$ & 107 & 12 & 0.9 (0.4 to 1.9$)$ & 83 & 36 & 1.9 (1.2 to 3.2$)$ \\
\hline \multicolumn{7}{|c|}{ Educational level† } \\
\hline Basic & 846 & 71 & reference & 761 & 156 & reference \\
\hline Secondary & 727 & 43 & 0.9 (0.6 to 1.5$)$ & 674 & 96 & 0.9 (0.6 to 1.2$)$ \\
\hline Higher & 407 & 17 & 1.1 (0.6 to 2.3) & 385 & 39 & 0.8 (0.5 to 1.3$)$ \\
\hline \multicolumn{7}{|l|}{ Annual income } \\
\hline Low & 489 & 48 & reference & 442 & 95 & reference \\
\hline Middle & 1010 & 67 & 0.7 (0.4 to 1.2$)$ & 929 & 148 & 0.9 (0.6 to 1.2$)$ \\
\hline High & 517 & 20 & $0.9(0.4$ to 1.8$)$ & 483 & 54 & $1.1(0.7$ to 1.9$)$ \\
\hline \multicolumn{7}{|l|}{ Year of surgery } \\
\hline 1996-2006 & 448 & 11 & 0.7 (0.3 to 1.7$)$ & 427 & 32 & 0.5 (0.3 to 0.9$)$ \\
\hline 2007-2008 & 739 & 52 & reference & 675 & 116 & reference \\
\hline 2009-2010 & 829 & 72 & $0.9(0.6$ to 1.4$)$ & 752 & 149 & $1.0(0.7$ to 1.4$)$ \\
\hline
\end{tabular}

risk, but it did not influence the estimates as much as the preoperative drug use, which was the strongest risk factor of postoperative drug use. More studies are needed to examine the possible impact of body mass index, menopausal status, the predominant type of incontinence and the relationship between time from diagnosis of UI to performed surgery and the following probability of receiving symptom-relieving drugs.

In conclusion, we found that a substantial number of women will continue to be prescribed symptom-relieving drugs after surgery for UI within a year of follow-up. Only a minority $(8.1 \%)$ of preoperative non-users initiated usage of symptom-relieving drugs after surgery. Compared with preoperative drug use, no other factors in the regression model contributed considerably to the OR of being a short-term or long-term postoperative user of symptomrelieving drugs. Counselling women prior to UI surgery should therefore include information on the high risk of continuing use after surgery for preoperative users of symptom-relieving drugs, and preoperative non-users have a risk—although it is low—of becoming a user.

Author affiliations

${ }^{1}$ Research Unit of Clinical Epidemiology, Institute of Clinical Research, University of Southern Denmark, Odense, Denmark

${ }^{2}$ Center for Clinical Epidemiology, Odense University Hospital, Odense, Denmark

${ }^{3}$ Department of Hospital Services and Emergency Management, Danish Health and Medicines Authority, Copenhagen, Denmark

${ }^{4}$ Department of Obstetrics and Gynecology, Aarhus University Hospital, Aarhus, Denmark

${ }^{5}$ Research Unit of Clinical Pharmacology, Institute of Public Health, University of Southern Denmark, Odense, Denmark

Contributors All authors have drafted the article, revised it critically for important intellectual content and approved the final version to be published. All the authors are responsible for the study concept and design and have participated in the interpretation of data. RG is the guarantor and has full access to all of the data in the study. 
Funding This study was funded by (1) Nordic Urogynaecology Association (NUGA) Research Grant, (2) A. P. Møller and Chastine Mc-Kinney Møller Foundation for General Purposes, (3) Center for Clinical Epidemiology, Odense University Hospital and (4) Region of Southern Denmark.

Competing interests None.

Ethics approval The study was approved by the Danish Data Protection Agency (no. 2009-41-3564). According to Danish law, ethical review board approval or patient consent is not required for register-based studies.

Provenance and peer review Not commissioned; externally peer reviewed.

Data sharing statement According to the Danish Data Detection Agency, we are not allowed to share our data from the Danish National Patient Registry. This would require special approval from the Danish Data Detection Agency and the Statens Serum Institut which deliver the data from the Danish National Patient Registry.

Open Access This is an Open Access article distributed in accordance with the Creative Commons Attribution Non Commercial (CC BY-NC 3.0) license, which permits others to distribute, remix, adapt, build upon this work noncommercially, and license their derivative works on different terms, provided the original work is properly cited and the use is non-commercial. See: http:// creativecommons.org/licenses/by-nc/3.0/

\section{REFERENCES}

1. Haylen BT, Ridder DDe, Freeman RM, et al. An International Urogynecological Association (IUGA)/International Continence Society (ICS) Joint Report on the Terminology for Female Pelvic Floor Dysfunction. Int Urogynecol J 2010;21:5-26.

2. Abrams P, Cardozo L, Wein A, et al. Incontinence: 4th International Consultation on Incontinence. Paris, France, 2009.

3. Nabi G, Cody JD, Ellis G, et al. Anticholinergic drugs versus placebo for overactive bladder syndrome in adults (review). Cochrane Database Syst Rev 2009;(4):CD003781.

4. Finney SM, Andersson K-E, Gillespie Jl, et al. Antimuscarinic drugs in detrusor overactivity and the overactive bladder syndrome: motor or sensory actions? BJU Int 2006;98:503-7.

5. Boy S, Reitz A, Wirth B, et al. Facilitatory neuromodulative effect of duloxetine on pudendal motor neurons controlling the urethral pressure: a functional urodynamic study in healthy women. Eur Urol 2006;50:119-25.

6. Ulmsten U, Petros P. Intravaginal slingplasty (IVS): an ambulatory surgical procedure for treatment of female urinary incontinence. Scand J Urol Nephrol 1995;29:75-82.

7. Rapp D, Kobashi K. The evolution of midurethral slings. Nat Clin Pract Urol 2008;5:194-201.

8. Kirchin V, Page T, Keegan PE, et al. Urethral injection therapy for urinary incontinence in women (review). Cochrane Database Syst Rev 2012;(2):CD003881.

9. Mohr S, Siegenthaler M, Mueller MD, et al. Bulking agents: an analysis of 500 cases and review of the literature. Int Urogynecol J 2013;24:241-7.

10. Kuo Y-C, Kuo H-C. Botulinum toxin injection for lower urinary tract dysfunction. Int J Urol 2013;20:40-55.

11. Ammendrup A, Bendixen $A$, Sander $P$, et al. Urinary incontinence surgery in Denmark 2001-2003. Ugeskr Laeger 2009;171:339-404. [Danish]

12. Cammu H, Saeys F, Haentjens P. Dramatic increase (1997-2007) in the number of procedures for stress urinary incontinence in Belgium. Int Urogyn J 2010;21:1511-15.

13. Segal JL, Vassallo B, Kleeman S, et al. Prevalence of persistent and de novo overactive bladder symptoms after the tension-free vaginal tape. Obstet Gynecol 2004;104:1263-9.

14. Yoo E-H, Kim D. Predictors of postoperative antimuscarinics in women with mixed urinary incontinence after transobturator surgery. Int Urogynecol J 2013;24:401-6.

15. Barber MD, Kleeman S, Karram MM, et al. Risk factors associated with failure 1 year after retropubic or transobturator midurethral slings. Am J Obstet Gynecol 2008;199:666.e1-7.

16. Lynge E, Sandegaard JL, Rebolj M. The Danish National Patient Register. Scand J Public Health 2011;39:30-3.
17. Andersen T, Madsen M, Jørgensen J, et al. The Danish National Hospital Register. A valuable source of data for modern health sciences. Dan Med Bull 1999;46:262-8.

18. World Health Organization. Manual of the International Statistical Classification of Diseases, Injuries, and Causes of Death (ICD-8). Geneva, Switzerland: WHO, 1967.

19. World Health Organization. Internatinal Classification of Diseases10th revision (ICD-10). 2013. http://www.who.int/classifications/ics/ en/ (accessed Apr 2013).

20. Nordic Medico-Statistical Committee. Classification of Surgical Procedures, version 1.15. no. 93:2010, Copenhagen.

21. Gaist D, Sørensen H, Hallas J. The Danish Prescription Registers. Dan Med Bull 1997;44:445-8.

22. Petersson F, Baadsgaard M, Thygesen LC. Danish registers on personal labour market affiliation. Scand J Public Health 2011;39:95-8

23. Charlson $\mathrm{M}$, Pompei $\mathrm{P}$, Ales $\mathrm{K}$, et al. A new method of classifying prognostic comorbidity in longitudinal studies: development and validation. J Chronic Dis 1987;40:373-83.

24. Schneeweiss S, Maclure M. Use of comorbidity scores for control of confounding in studies using administrative databases. Int $J$ Epidemiol 2000;29:891-8.

25. Thygesen SK, Christiansen CF, Christensen S, et al. The predictive value of ICD-10 diagnostic coding used to assess Charlson comorbidity index conditions in the population-based Danish National Registry of Patients. BMC Med Res Methodol 2011;11:83.

26. Thomsen R, Riis A, Christensen S, et al. Diabetes and 30-day mortality from a Danish population-based cohort study. Diabetes Care 2006;29:805-10.

27. Dalton SO, Steding-Jessen M, Engholm G, et al. Social inequality and incidence of and survival from lung cancer in a population-based study in Denmark, 1994-2003. Eur J Cancer 2008;44:1989-95.

28. Andersen T, Madsen M, Loft A. Validity of surgical information from the Danish National Patient Registry with special attention to the analysis of regional variations in hysterectomy rates. Ugeskr Laeger 1987;149:2420-2. [Danish]

29. Mosbech J, Jørgensen J, Madsen M, et al. The national patient registry Evaluation of data quality. Ugeskr Laeger 1995;157:3741-5. [Danish]

30. Ottesen M. Validity of the registration and reporting of vaginal prolapse surgery. Ugeskr Laeger 2009;171:404-8. [Danish]

31. Stav K, Dwyer PL, Rosamilia A, et al. Risk factors of treatment failure of midurethral sling procedures for women with urinary stress incontinence. Int Urogynecol J 2010;21:149-55.

32. Richter HE, Brubaker L, Stoddard AM, et al. Patient related factors associated with long-term urinary continence after Burch colposuspension and pubovaginal fascial sling surgeries. J Urol 2012;188:485-9.

33. Ankardal M, Heiwall B, Lausten-Thomsen N, et al. Short- and long-term results of the tension-free vaginal tape procedure in the treatment of female urinary incontinence. Acta Obstet Gynecol Scand 2006;85:986-92.

34. Chawla A, Reddy S, Thomas J. Risk factors for persistent stress urinary incontinence after mid-urethral procedures. Indian J Urol 2008;24:130-1.

35. Richter HE, Diokno A, Kenton K, et al. Predictors of treatment failure 24 months after surgery for stress urinary incontinence. J Urol 2008;179:1024-30.

36. Chapple C, Khullar V, Gabriel Z, et al. The effects of antimuscarinic treatments in overactive bladder: a systematic review and metaanalysis. Eur Urol 2005;48:5-26.

37. Brostrøm S, Hallas J. Persistence of antimuscarinic drug use. Eur J Clin Pharmacol 2009;65:309-14

38. Vella M, Duckett J, Basu M. Duloxetine 1 year on: the long-term outcome of a cohort of women prescribed duloxetine. Int Urogynecol $J$ 2008;19:961-4.

39. Wagg A, Compion G, Fahey A, et al. Persistence with prescribed antimuscarinic therapy for overactive bladder: a UK experience. BJU Int 2012;110:1767-74.

40. Barber MD, Gustilo-Ashby AM, Chen CCG, et al. Perioperative complications and adverse events of the MONARC transobturator tape, compared with the tension-free vaginal tape. Am J Obstet Gynecol 2006;195:1820-5.

41. Svenningsen R, Borstad E, Spydslaug AE, et al. Occult incontinence as predictor for postoperative stress urinary incontinence following pelvic organ prolapse surgery. Int Urogynecol $J$ 2012;23:843-9. 